\title{
Polarization, Isopotential Maps and Tunneling in Guanine, Cytosine, and Tautomeric Forms
}

\author{
Julio Marañon and Oscar M. Sorarrain \\ Departamento de Fisica, Facultad de Ciencias Exactas, Universidad Nacional de La Plata, \\ La Plata, Argentina \\ Z. Naturforsch. 33 c, 23-27 (1978); received November 2, 1977 \\ Polarization, Isopotential, Tunneling, Guanine, Cytosine \\ We have used the CNDO/2-CI method to calculate the isopotential maps for the fundamental \\ state and the direction of the polarizations corresponding to several singlet transitions in the mole- \\ cules of guanine, cytosine and tautomeric forms. \\ We have also calculated the times for proton tunneling and equilibrium constants between both \\ conformers corresponding to the fundamental and some excited states. \\ The results have been compared with the available experimental data.
}

\section{Introduction}

The electronic structure of the nucleic basis and their tautomeric forms have been discussed by several authors $[1-4]$. In this paper we are following our former studies about the normal and tautomeric conformations for the molecules of guanine and cytosine using the CNDO/2-Cl method for the calculations.

We have considered in this report the direction of the polarizations involved in several singlet transitions. The obtained results are compared with the available experimental ones; moreover, we are shown a set of isopotential curves. These curves are deeply concerned with the qualitative predictions about the centers for electrophilic or nucleophilic attack in both conformations: normal and tautomeric.

The barriers formerly calculated [1] have been also used to determine tunneling times for the proton movement and the equilibrium constants between the conformers in a group of excited states in both molecules.

\section{Employed Method and Results}

We have considered:

a) Direction for the polarizations in a set of singlet transitions

The direction of the polarizations corresponding to the observed singlet transitions are very interesting because they are closely related with the op-

Requests for reprints should be sent to Prof. J. Marañon, or O. M. Sorarrain, Facultad de Ciencias Exactas, Departamento de Fisica, Calle 115 y 49 c.C. No. 67, La Plata, Argentina.

Miembros carrera del investigator CONICET-ARGENTINA. tical properties and the energy transfer in the DNA. These directions have been analysed in several theoretical [2-9] and experimental papers [1015]. In general, there is far from full agreement between the experimental and theoretical studies. The main reason is perhaps that the calculations have been done in molecules without substituting elements and the measures are mainly available in substituted molecules, moreover, there is not agreement between some experimental analysis, i.e.: for the direction of the polarization corresponding to $\lambda_{\max }$ in 9-ethylguanine there is a $20^{\circ}$ difference between references [13] and [14].

From the considerations given above we have undertaken the calculation of the direction for the polarization of several singlet transitions in both molecules, the results are shown in Fig. 1.

For the energy levels and oscillator strength values, we have obtained the Table I.
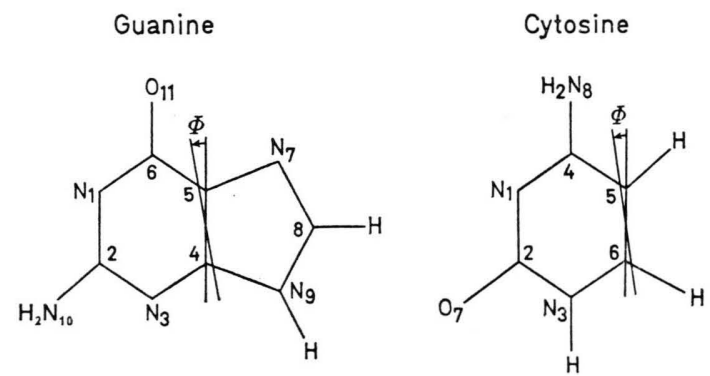

Fig. 1. Polarization directions. Positive sense counter clockwise.

These calculations for the molecule of guanine should be compared with the experimental measures of Callis [11, 13] for the 9-ethylguanine and Fucaloro [14]. Both authors are in agreement to report two directions almost perpendicular for the 
Table I a. Direction of polarizations in guanine.

\begin{tabular}{|c|c|c|c|c|c|}
\hline \multicolumn{3}{|c|}{ Normal form } & \multicolumn{3}{|c|}{ Tautomeric form } \\
\hline $\begin{array}{l}\text { Energy } \\
{[\mathrm{eV}]}\end{array}$ & $\begin{array}{l}\text { Osc. } \\
\text { strength }\end{array}$ & $\Phi^{*}$ & $\begin{array}{l}\text { Energy } \\
{[\mathrm{eV}]}\end{array}$ & $\begin{array}{l}\text { Osc. } \\
\text { strength }\end{array}$ & $\Phi *$ \\
\hline 3.75 & $(0.17)$ & $-95^{\circ}$ & 4.08 & $(0.03)$ & $20^{\circ}$ \\
\hline 4.59 & $(0.15)$ & $-30^{\circ}$ & 4.54 & $(0.20)$ & $-50^{\circ}$ \\
\hline 5.06 & $(0.01)$ & $20^{\circ}$ & 5.36 & $(0.10)$ & $55^{\circ}$ \\
\hline
\end{tabular}

Table I b. Direction of polarizations in cytosine.

\begin{tabular}{|c|c|c|c|c|c|}
\hline \multicolumn{3}{|c|}{ Normal form } & \multicolumn{3}{|c|}{ Tautomeric form } \\
\hline $\begin{array}{l}\text { Energy } \\
{[\mathrm{eV}]}\end{array}$ & $\begin{array}{l}\text { Osc. } \\
\text { strength }\end{array}$ & $\Phi *$ & $\begin{array}{l}\text { Energy } \\
{[\mathrm{eV}]}\end{array}$ & $\begin{array}{l}\text { Osc. } \\
\text { strength }\end{array}$ & $\Phi *$ \\
\hline 4.10 & $(0.11)$ & $-36^{\circ}$ & 4.67 & $(0.33)$ & $-18^{\circ}$ \\
\hline 5.43 & $(0.01)$ & $55^{\circ}$ & 5.53 & $(0.02)$ & $34^{\circ}$ \\
\hline 6.03 & $(0.53)$ & $45^{\circ}$ & 5.81 & $(0.09)$ & $-5^{\circ}$ \\
\hline
\end{tabular}

* $\Phi$ defined in the same way than references $[16,18]$. Positive sence is counter clockwise.

polarizations of the observed transitions. Our theoretical results are in accord with these conclusions, moreover the lowest frequency line is given almost in the longitudinal direction of the guanine molecule (see Fig. 1 and Table Ia). In Table I a, we are also reporting a third line $(5.06 \mathrm{eV})$ practical ly in the same direction than the second one (4.59 $\left.\mathrm{eV},-50^{\circ}\right)$. The $(5.06 \mathrm{eV})$ transition has been found experimentally by Borrensen [17].

For the tautomeric guanine the direction of the polarizations corresponding to the same lines present noticeable changes; but their direction of the polarizations remain in the same way rather perpendicular.

In a similar analysis for the molecule of cytosine, the polarization of the lowest transition is rather in the $\mathrm{C}_{5}=\mathrm{C}_{6}$ direction, meanwhile the $5.43 \mathrm{eV}$ and $6.03 \mathrm{eV}$ are rather perpendicular one (see Table $\mathrm{I} b$ ). The experimental measures $[13,14]$ are in agreement with our results for the first and third transitions, on the contrary, for the second line the polarization should be preferentially in the same direction than the first one.

For the tautomeric cytosine the three reported transitions are mainly in the $\mathrm{C}_{5}=\mathrm{C}_{6}$ direction (see, Table I b) .

\section{b) Isopotential curves}

For the theoretical determination of the centers for the electrophilic and nucleophilic attack from the electronic charge distributions in molecules, is certainly useful to make the isopotential maps. Bonnaccorsi [19] has derived the following formula for the electrostatic potential.

$$
V_{\mathrm{p}}=\sum_{A} \frac{Z_{\mathrm{A}}}{R_{\mathrm{pA}}}-\Sigma P_{\nu} \int \frac{\chi_{\mu} \chi_{v}}{r_{\mathrm{p}}} \mathrm{d} \tau
$$

where $R_{\mathrm{pA}}$ is the distance from the proton $\mathrm{p}$ to the atomic nuclei A, $P_{\mu \nu}$ define the density matrix elements for the $\mu, v$ atomic orbitals, and the integral is given by the coulombic attraction between the proton and the electronic charge distribution $\chi_{\mu} \chi_{\nu}$. Another expression more suitable to use with semiempirical methods has been given by Giessner-Prettre $[20]$ in the following way:

$$
V_{\mathrm{p}}=\sum_{A}\left(\frac{Z_{\mathrm{A}}}{R_{\mathrm{pA}}}-P_{\mathrm{AA}} V_{\mathrm{AP}}\right)
$$

where $P_{\mathrm{AA}}$ is the electronic density for the atom A. The $V_{\mathrm{AP}}$ are the nuclear attraction integrals for the $\mathrm{s}$ orbitals located on the same element.

The formulas of ref. [19] and [20] have been applied to the nucleic basis and the numerical results compared with the experimental data [2023]. In this paper we have used formula (2) to compare the normal and tautomeric conformations in both molecules.

The isopotential curves in the molecular plane for the normal and tautomeric guanine are shown in Fig. 2.

In this figure (see, 2 a) we can observe an attractive valley for the electrophilic attack located in the region between the $\mathrm{O}_{11}$ and $\mathrm{N}_{7}$ atoms. In this valley there is not a directional gradient along the $\mathrm{C}_{6}=\mathrm{O}_{11}$ direction corresponding to the carbonyl group. This result follows from a $120^{\circ}$ angle between a couple of lone pair orbitals containing the $\mathrm{C}_{6}=\mathrm{O}_{11}$ direction. In other words, there is an attraction from the $\mathrm{N}_{7}$ atom and a repulsive effect of the $\mathrm{N}_{1}-\mathrm{H}$ bond with the minimum toward the $\mathrm{N}_{7}$ element. Moreover, there is another center for protonic attack located in the $\mathrm{N}_{3}$ atom. These theoretical results are in agreement with the experimental ones for protonation and alkylation in normal guanine [22].

The tautomeric guanine (Fig. $2 \mathrm{~b}$ ) has not a well defined attractive region between the $\mathrm{O}_{11}$ and $\mathrm{N}_{7}$ elements. In this conformer a center for protonic attack arise in the neighborhood of the $\mathrm{N}_{7}$ atom. There are also two possible centers on the $\mathrm{N}_{1}$ and $\mathrm{N}_{3}$ atoms. The isopotentials near the $\mathrm{N}_{3}$ atom are 

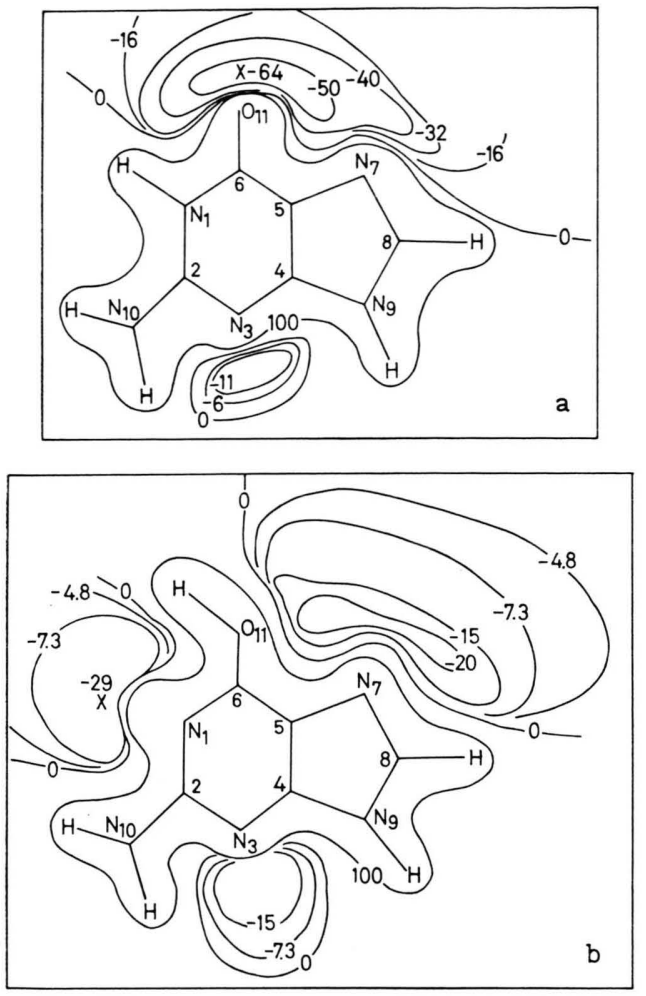

Fig. 2 a. Guanine, Normal form. Isopotential map. Values in kcal.

Fig. 2 b. Guanine, Tautomeric form. Isopotential map. Values in kcal.

quite similar in normal and tautomeric guanine. The calculations presented in this paper for the molecule of guanine are in the whole in agreement with former ones given by Jordan [24], Kleiner [25]. These authors are in accord to point out the $\mathrm{N}_{1}, \mathrm{~N}_{3}$ and $\mathrm{N}_{7}$ atoms as centers for an electrophilic attack in guanine.

The isopotential curves for the normal and tautomeric cytosine are given in Fig. 3.

For the normal cytosine (Fig. 3 a) there is a potential valley between the $\mathrm{N}_{3}$ atom and the $\mathrm{C}_{2}=\mathrm{O}_{7}$ carbonyl group. This result is in agreement with former theoretical and experimental studies $[9,21,22,24,26]$. For these authors the $\mathrm{N}_{3}$, $\mathrm{C}_{2}=\mathrm{O}_{7}$ and $\mathrm{N}_{8}$ are possible centers for protonic attack, i.e.: Hug [9] has calculated the theoretical spectra for the $\mathrm{N}$ protonated cytosine, this spectra is in accord with the experimental one for cytidine in $\mathrm{pH} 2.5$.

For the tautomeric cytosine (Fig. $3 \mathrm{~b}$ ) the electrophilic centers are given in the $\mathrm{C}_{2}=\mathrm{O}_{7}$ and $\mathrm{N}_{8}$ elements.
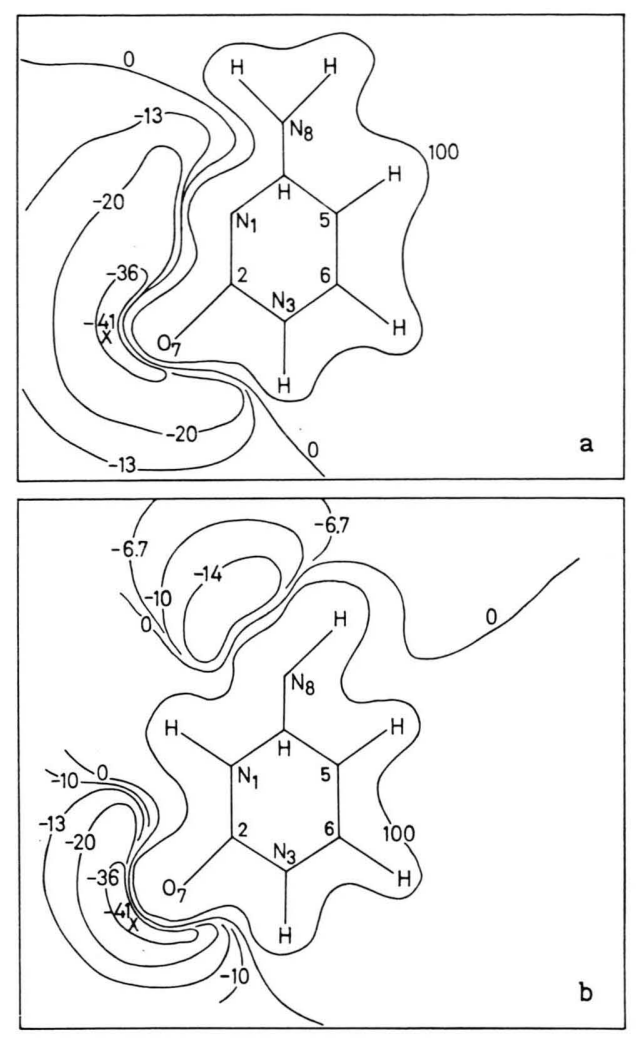

Fig. 3 a. Cytosine. Normal form. Isopotential map. Values in kcal.

Fig. 3 b. Cytosine. Tautomeric form. Isopotential map. Values in kcal.

\section{c) Tunneling and equilibria between conformers}

In a previous paper [1] we have determined a group of barriers between the normal and tautomeric conformers corresponding to several excited states for the molecules of guanine and cytosine. Now, we have used these barriers to calculate times for proton tunneling and equilibrium constants. For this purpose, we have employed the formalism developed by Löwdin [4] and Rein [27]. The results are shown in Tables II and III.

For the molecule of guanine the $\tau$ value for the fundamental state predicts a slow barrier with a very little probability for proton tunneling, meanwhile for the excited states there are fast barriers with high probabilities, that is, phototautomerization seems to be certainly possible. This conclusion is quite similar than a previous one for adenine [28].

In the molecule of cytosine the barriers for all states (fundamental and excited ones) are fast ones 
Table II. Proton tunneling and equilibrium constants between normal and tautomeric forms of the molecule guanine.

\begin{tabular}{lrlllll}
\hline State & $\mathrm{s}$ & $\mathrm{g}$ & $\begin{array}{l}v_{\mathrm{T}} \\
{\left[\mathrm{sec}^{-1}\right]}\end{array}$ & $\begin{array}{l}v_{\mathrm{N}} \\
{\left[\mathrm{sec}^{-1}\right]}\end{array}$ & $\begin{array}{l}\tau \\
{[\mathrm{sec}]}\end{array}$ & $\begin{array}{l}n T \\
n N\end{array}$ \\
\hline$(\mathrm{G}-\mathrm{S})$ & 39.02 & $1.28 \times 10^{-34}$ & $4.00 \times 10^{12}$ & $2.78 \times 10^{12}$ & $1.15 \times 10^{21}$ & $6.30 \times 10^{-25}$ \\
$1 \sigma \rightarrow \pi^{*}(\mathrm{~s})$ & 5.10 & $3.72 \times 10^{-5}$ & $2.04 \times 10^{12}$ & $1.56 \times 10^{12}$ & $7.46 \times 10^{-9}$ & 4.96 \\
$4 \sigma \rightarrow \pi^{*}(\mathrm{~s})$ & 6.95 & $9.19 \times 10^{-7}$ & $1.00 \times 10^{12}$ & $2.04 \times 10^{12}$ & $3.58 \times 10^{-7}$ & $3.13 \times 10^{-1}$ \\
$1 \sigma \rightarrow \pi^{*}(\mathrm{~T})$ & 3.45 & $1.01 \times 10^{-3}$ & $2.04 \times 10^{12}$ & $1.24 \times 10^{12}$ & $3.01 \times 10^{-10}$ & $1.66 \times 10^{-2}$ \\
$1 \pi \rightarrow \pi^{*}(\mathrm{~T})$ & 3.08 & $2.11 \times 10^{-3}$ & $1.24 \times 10^{12}$ & $4.00 \times 10^{12}$ & $9.04 \times 10^{-11}$ & $4.32 \times 10^{-5}$ \\
\hline
\end{tabular}

Table III. Proton tunneling and equilibrium constants between normal and tautomeric forms of the molecule cytosine.

\begin{tabular}{lrlllll}
\hline State & $\mathrm{s}$ & $\mathrm{g}$ & $\begin{array}{l}v_{\mathrm{T}} \\
{\left[\mathrm{sec}^{-1}\right]}\end{array}$ & $\begin{array}{l}v_{\mathrm{N}} \\
{\left[\mathrm{sec}^{-1}\right]}\end{array}$ & $\begin{array}{l}\tau \\
{[\mathrm{sec}]}\end{array}$ & $\begin{array}{l}n=\frac{n}{n N} \\
\end{array}$ \\
\hline $\mathrm{G}-\mathrm{S})$ & 48.52 & $7.18 \times 10^{-43}$ & $2.78 \times 10^{12}$ & $2.04 \times 10^{12}$ & $2.89 \times 10^{29}$ & $2.04 \times 10^{-5}$ \\
$1 \sigma \rightarrow \pi^{*}(\mathrm{~s})$ & 4.74 & $7.64 \times 10^{-5}$ & $8.27 \times 10^{12}$ & $2.37 \times 10^{12}$ & $1.23 \times 10^{-9}$ & $4.63 \times 10^{-4}$ \\
$1 \pi \rightarrow \pi^{*}(\mathrm{~T})$ & 3.42 & $1.07 \times 10^{-3}$ & $1.00 \times 10^{12}$ & $1.38 \times 10^{12}$ & $3.93 \times 10^{-10}$ & $1.37 \times 10^{-5}$ \\
$2 \sigma \rightarrow \pi^{*}(\mathrm{~T})$ & 3.95 & $3.70 \times 10^{-4}$ & $8.27 \times 10^{12}$ & $1.56 \times 10^{12}$ & $2.75 \times 10^{-10}$ & $9.87 \times 10^{-5}$ \\
\hline
\end{tabular}

$\mathrm{T}$, Tautomeric; $(\mathrm{G}-\mathrm{S})$, ground state; N, normal.

with high probabilities, that is, thermo and phototautomerization seems to be possible for this molecule.

\section{Conclusions}

If we compare the calculations for the normal and tautomeric conformer presented in the former paragraph, we can summarized as following:

1) The tautomerization noticeable changes the direction for the polarizations corresponding to the $\pi-\pi^{*}$ and $n-\pi^{*}$ transitions (those lines given in Table I).

[1] J. Marañon and O. M. Sorarrain, Z. Naturforsch. 32 c, 870 (1977).

[2] A. Bullman and B. Pullman, Advances in Quantum Chemistry, vol. 4, 267, Academic Press, New YorkLondon 1968.

[3] B. Pullman and A. Pullman, Advances in Heterocyclic Chemistry 13, 77, Academic Press, New York-London 1971.

[4] P. O. Löwdin, Technical Report QB7, Quantum Chemistry Group, University of Uppsala 1963.

[5] H. Morita and S. Nagakura, Theor. Chim. Acta (Berl.) 11, 279 (1968).

[6] H. Berthold, C. Giessner-Prettre, and A. Pullman, Int. J. Quantum Chem. 1, 123 (1967).

[7] J. Ladik and K. Appel, Theor. Chim. Acta (Berl.) 4, 132 (1966).

[8] D. L. Breen and R. L. Flurry, Theor. Chem. Acta (Berl.) 23, 138 (1971).
2) The tautomerization also modifyes the centers for protonic attack in both molecules.

3) There is a different behaviour in the molecule of cytosine compared with the other nucleic basis. For this molecule there is a large probability for thermo-tautomerization.

4) For both nucleic basis (really for adenine and thymine also) the probabilities of photo-tautomerization are high enough to be considered.

We are grateful to Consejo Nacional de Investigaciones de Argentina and Organization of the American States for their economic aid during the development of this paper.

[9] W. Hug and I. Tinoco, Jr., J. Amer. Chem. Soc. 95, 2803 (1973)

[10] R. F. Stewart and N. Davidson, J. Chem. Phys. 39, 255 (1963).

[11] P. R. Callis, E. J. Rosa, and W. T. Simpson, J. Amer. Chem. Soc. 86, 2292 (1964).

[12] L. B. Clark and I. Tinoco, Jr., J. Amer. Chem. Soc. 87, 11 (1965).

[13] P. R. Callis, B. Fanconi, and W. T. Simpson, J. Amer. Chem. Soc. 93, 6677 (1971).

[14] A. F. Fucaloro and L. S. Fosters, J. Amer. Chem. Soc. 93, 6643 (1971).

[15] P. R. Callis and W. T. Simpson, J. Amer. Chem. Soc. 92, 3593 (1970).

[16] H. De Voe and I. Tinoco, Jr., J. Mol. Biol. 4, 500 (1962).

[17] H. C. Borrensen, Acta Chem. Scand. 21, 920 (1967).

[18] H. De Voe and P. Tinoco, Jr., J. Mol. Biol. 4, 518 (1962). 
[19] R. Bonnaccorsi, E. Scrocco, and J. Tomassi, J. Chem. Phys. 52, 5270 (1970).

[20] C. Giessner-Prettre and A. Pullman, Theor. Chim. Acta (Berl.) 25, 83 (1972).

[21] R. Bonnaccorsi, A. Pullman, E. Scrocco, and J. Tomassi, Theor Chim. Acta (Berl.) 24, 51 (1972)

[22] C. Giessner-Prettre and A. Pullman, Theor. Chim. Acta (Berl.) 33, 91 (1974).

[23] R. Bonnaccorsi, E. Scrocco, J. Tomassi, and A. Pullman, Theor. Chim. Acta 36, 339 (1975).
[24] F. Jordan and H. D. Sostman, J. Amer. Chem. Soc. 95, 6544 (1973).

[25] M. Kleiner and M. Elder, Mol. Phys. 30, 357 (1975).

[26] R. M. Izatt, J. J. Christensen, and J. H. Ry Huig, Chem. Rev. 71, 439 (1971).

[27] R. Rein and F. E. Harris, J. Chem. Phys. 42, 2177 (1965).

[28] J. Marañon and O. M. Sorarrain, to be published. 